\title{
EVALUATION OF THE PERFORMANCE OF SAR AND SAR-OPTICAL FUSED DATASET FOR CROP DISCRIMINATION
}

\author{
Sk. Mustak ${ }^{1, *}$, Gowri Uday ${ }^{1}$, Balaji Ramesh ${ }^{1}$, Bushra Praveen $^{2}$ \\ ${ }^{1}$ Ecoinformatics Lab, Ashoka Trust for Research in Ecology and the Environment, Bangalore, India - mustak.sk@atree.org \\ ${ }^{2}$ Indian Institute of Technology, Indore
}

Commission III WG III/10

KEY WORDS: Machine Learning, Earth Observation, Kernel Optimization, Feature Selection, Land Use and Cover

\begin{abstract}
:
Crop discrimination and acreage play a vital role in interpreting the cropping pattern, statistics of the produce and market value of each product. Sultan Battery is an area where a large amount of irrigated and rainfed paddy crops are grown along with Rubber, Arecanut and Coconut. In addition, the northern region of Sultan Battery is covered with evergreen and deciduous forest. In this study, the main objective is to evaluate the performance of optical and Synthetic Aperture Radar (SAR)-optical hybrid fusion imageries for crop discrimination in Sultan Bathery Taluk of Wayanad district in Kerala. Seven land use classes such as paddy, rubber, coconut, deciduous forest, evergreen forest, water bodies and others land use (e.g., built-up, barren etc.) were selected based on literature review and local land use classification policy. Both Sentinel-2A (optical) and sentinel-1A (SAR) satellite imageries of 2017 for Kharif season were used for classification using three machine learning classifiers such as Support Vector Machine (SVM), Random Forest (RF) and Classification and Regression Trees (CART). Further, the performance of these techniques was also compared in order to select the best classifier. In addition, spectral indices and textural matrices (NDVI, GLCM) were extracted from the image and best features were selected using the sequential feature selection approach. Thus, 10-fold cross-validation was employed for parameter tuning of such classifiers to select best hyperparameters to improve the classification accuracy. Finally, best features, best hyperparameters were used for final classification and accuracy assessment. The results show that SVM outperforms the RF and CART and similarly, Optical+SAR datasets outperforms the optical and SAR satellite imageries. This study is very supportive for the earth observation scientists to support promising guideline to the agricultural scientist, policy-makers and local government for sustainable agriculture practice.
\end{abstract}

\section{INTRODUCTION}

Classification of crop types from the satellite imagery is a challenging task because; crops are more related to seasons, mixed growing pattern (e.g., mixed farming; sometimes boundary of Kharif, Rabi and Zaid season of a particular crop is not very clear) and rapid change of cropping pattern (Cai et al., 2018). Mapping crop types is essential in agricultural management because it helps the local government and policymakers to monitor the crop yield, tracking crop shown mapping different crops with the use of multispectral images (Song et al., 2017; Sonobe et al., 2017). However, the usage of multispectral satellite images (e.g., optical) has its own limitations due to the atmospheric factors. This can be further overcome by taking the aid of microwave remote sensing which uses microwave region of the spectrum for collecting data from the landscape. As microwave remote sensing has an ability to overcome the effects of clouds and can provide cloud-free images of the landscape despite the other weather conditions too (e.g., rain, haze etc.) (Steele-Dunne et al.,2017). Furthermore, others properties of microwave remote sensing such as backscatter, surface roughness and dialectic constant of the earth's object are the added advantages over optical remote sensing (Engman \& Chauhan, 1995; Steele-Dunne et al., 2017). With the advancement of image classification techniques, selection of best algorithm is very crucial to improve the overall classification accuracy. In this regard, machine learning rotation cycle, estimating the economic outcome from agriculture (Cai et al., 2018; Song et al., 2017). In addition, mapping of crop types also helps for the assessment of vulnerability of the crops in case of disasters (Song et al., 2017).

Remote sensing acts as an efficient solution for this purpose due to the availability of a wide range of satellite imagery products with high temporal and spatial resolutions. Studies have

algorithm is efficient, fast and robust as compared to parametric traditional classifiers (e.g., Maximum Likelihood Classifier) (Balzter et al., 2015; Shao \& Lunetta, 2012; Mustak, 2018).

In this study, optical data from Sentinel 2 is used along with Sentinel 1A GRDH and SLC data. With the launch of Sentinel$1 \mathrm{~A}, \mathrm{VV}$ and $\mathrm{VH}$ polarization data is available with a revisit period of 6 days with a spatial resolution of approximately $20 \mathrm{x}$ $5 \mathrm{~m}$ using the Interferometric Wide Swath mode (IW) which was widely used in several studies (e.g., Balzter et al., 2015). In addition, optical data is further fused with the SAR data using image fusion techniques (e.g., High Pass Filter) for reducing the impact of the atmosphere and also to increase the spatial and spectral resolution for better crop discrimination (Gaetano et al., 2017). The main objective of this paper is to evaluate

\footnotetext{
* Corresponding author
} 
performance of optical, Synthetic Aperture Radar (SAR) and optical-SAR fused imageries for crop discrimination in Sultan Bathery Taluk of Wayanad district in Kerala using machine learning algorithms. Following crops such as paddy, rubber, coconut and Arecanut have considered for the discrimination in this study. This paper is structured in following sections such as, section 1: described about the overview of the study; section 2: explained about study area; Section 3: described about methodology; section 4: covers results and discussion, conclusion and recommendation. At the end of this article list of references have presented.

\section{STUDY AREA AND DATASETS USED}

\subsection{Study area}

The Sultan Bathery region of Wayanad district in the state of Kerala, both staple crops such as paddy and cash crops such as Coffee, Rubber, Coconut and Arecanut are grown. In this region, cash crops play a vital role in the livelihood of the people compared to the staple ones. The study area is the part of Bathery taluk of Wayanad District in Kerala which is shown in figure 1 . This area is located in between $76^{\circ} 5^{\prime} \mathrm{E}$ to $76^{\circ} 27^{\prime} \mathrm{E}$ and $11^{0} 34^{\prime} \mathrm{N}$ to $11^{0} 52^{\prime} \mathrm{N}$ covering with an area of $752 \mathrm{sq}$. $\mathrm{km}$. The region is covered with forests, lakes, reservoir, agricultural lands, plantations, and population centres (e.g., settlements). In addition, major part of this region is covered by forests which divided the region into the eastern and northern sides. In this area, five major crops are grown such as paddy, rubber, coconut, coffee and Arecanut in which Coffee and Rubber are the dominated cash crops. As coffee is grown along with rubber, coconut or Arecanut, they are hard to be identified using satellite imageries. As per the phenology, paddy is cultivated during the Kharif season and is harvested by the end of November.

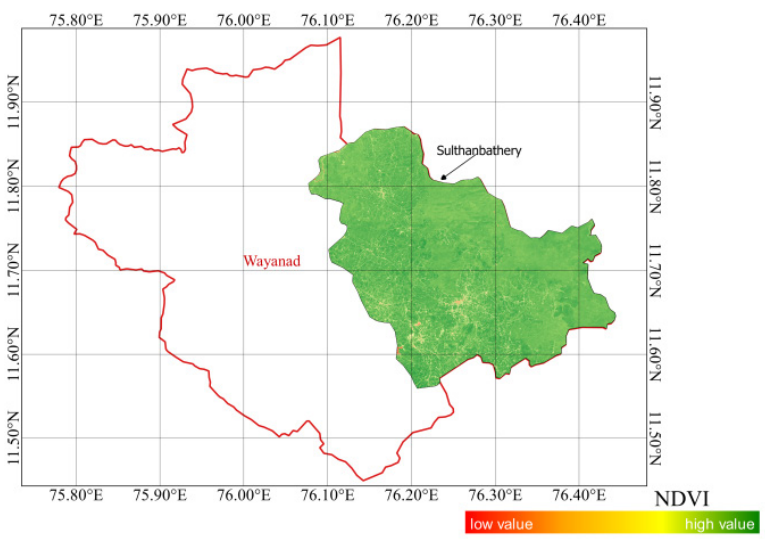

Figure 1. Location of study area

This area is belonging to undulating elevated landscape which varies from $700 \mathrm{~m}$ to $1075 \mathrm{~m}$ height above mean sea level. In addition, this area is also belongs to rain fed moon climate (Am of Koppen scheme) whereas average maximum and minimum temperature are $30.10^{\circ} \mathrm{C}$ and $15.60^{\circ} \mathrm{C}$ (annual average $22.5^{\circ} \mathrm{C}$ ) with annual average rainfall is $2681 \mathrm{~mm}$ respectively (IMPRINT, 2018). The region experiences three seasons, summer (March to May), winter (December to February) and monsoon (June and December). The region receives rain from both the south-east and north-west monsoon.

\subsection{Datasets and software used}

In this study, Sentinel 1A and Sentinel-2A MSI were used. Sentinel-1A download from the Alaska Satellite Facility (https://www.asf.alaska.edu/) while sentinel-2A MSI using google earth engine. The optical data (e.g., Sentinel-2A MSI) is consists of thirteen bands while Senetil-1A is single band SAR imagery (See table 1, 2 and 3). Out of thirteen bands of Sentinel-2A MSI, only ten bands were used ignoring the coastal aerosol, water vapour and Cirrus bands as they are mainly used for cloud screening and atmospheric correction. Temporal resolution of Sentinel 2A is 5 days. The Level-1C data (e.g., corrected images) scenes are acquired for the month of October and the cloud-free scenes are mosaicked to get the final image.

Secondly, Sentinel-1A (level-1) is a dual-polarization C-band (central frequency of $5.405 \mathrm{GHz}$ ) Synthetic Aperture Radar (SAR). This comprises of SLC (Single Look Complex) and GRD (Ground Range Detected) in both VV and VH polarization. The GRD data has the amplitude data while the SLC data is complex number preserving the phase information. SAR data is acquired by Interferometric Wide Swath mode and its temporal resolution is 12 days. The SLC data was used along with GRD to take the advantages of polarimetric decomposition to improve the classification accuracy.

\begin{tabular}{|c|c|c|c|}
\hline $\begin{array}{c}\text { Acquisition } \\
\text { date }\end{array}$ & Data Set & Sensor & Source \\
\hline $\begin{array}{c}25 \text { th October } \\
2017\end{array}$ & $\begin{array}{c}\text { SAR } \\
\text { GRDH \& } \\
\text { SLC }\end{array}$ & $\begin{array}{c}\text { Sentinel } \\
1 \mathrm{~A}\end{array}$ & $\begin{array}{c}\text { Alaska } \\
\text { Satellite } \\
\text { Facility }\end{array}$ \\
\hline October 2017 & Optical & $\begin{array}{c}\text { Sentinel } \\
2 \mathrm{~A}\end{array}$ & $\begin{array}{c}\text { Copernicus } \\
\text { Open Access } \\
\text { Hub }\end{array}$ \\
\hline $\begin{array}{c}\text { February 2000 } \\
\text { 26th October } \\
\text { 2018 } \\
\text { and }\end{array}$ & $\begin{array}{c}\text { Field Data, } \\
\text { Bhuvan } \\
\text { LULC, } \\
\text { Local } \\
\text { Knowledge }\end{array}$ & SRTM & $\begin{array}{c}\text { USGS Earth } \\
\text { Explorer }\end{array}$ \\
\hline
\end{tabular}

Table 1. Datasets used

\begin{tabular}{|l|c|c|c|}
\hline Band name & $\begin{array}{c}\text { Resolution } \\
(\mathbf{m})\end{array}$ & $\begin{array}{c}\text { Central } \\
\text { wavelen } \\
\text { gth } \\
\text { (nm) }\end{array}$ & $\begin{array}{c}\text { Band } \\
\text { width } \\
\text { (nm) }\end{array}$ \\
\hline B01(Coastal Aerosol) & 60 & 443 & 20 \\
\hline B02(Blue) & 10 & 490 & 65 \\
\hline B03(Green) & 10 & 560 & 35 \\
\hline B04(Red) & 10 & 665 & 30 \\
\hline B05(Vegetation Red Edge) & 20 & 705 & 15 \\
\hline B06(Vegetation Red Edge) & 20 & 740 & 15 \\
\hline B07(Vegetation Red Edge) & 20 & 783 & 20 \\
\hline B08(Near infrared) & 10 & 842 & 115 \\
\hline B08A(Vegetation Red Edge) & 20 & 865 & 20 \\
\hline
\end{tabular}




\begin{tabular}{|l|c|c|c|}
\hline B09(Water vapour) & 60 & 945 & 20 \\
\hline B10(Cirrus) & 60 & 1375 & 30 \\
\hline B11(SWIR) & 20 & 1610 & 90 \\
\hline B12(SWIR) & 20 & 2190 & 180 \\
\hline
\end{tabular}

Table 2. Radiometric details of Sentinel-2A

\begin{tabular}{|c|c|c|c|c|}
\hline $\begin{array}{c}\text { Band } \\
\text { name }\end{array}$ & Polarization & $\begin{array}{c}\text { Resolution } \\
(\mathbf{m})\end{array}$ & $\begin{array}{c}\text { Range } \\
(\mathbf{n m})\end{array}$ & $\begin{array}{c}\text { Band width } \\
(\mathbf{n m})\end{array}$ \\
\hline C - Band & VH & 10 & $\begin{array}{c}1530- \\
1565\end{array}$ & 35 \\
\hline C - Band & VV & 10 & $\begin{array}{c}1530- \\
1565\end{array}$ & 35 \\
\hline
\end{tabular}

Table 3. Radiometric details of Sentinel-1A

This study was carried using SNAP, Erdas Imagine (2014), ArcGIS 10.6.1 and google earth engine.

\section{METHODOLOGY}

The main objective of this paper is to evaluate the performance of optical, Synthetic Aperture Radar (SAR) and optical-SAR fused imageries for crop discrimination in Sultan Bathery Taluk of Wayanad district in Kerala using machine learning algorithms. Based on the main objectives following methods have been employed in this study.

\subsection{Crop Phenology}

Phenology refers to the study of life cycle of crop growth stages from sowing to harvest. Phenology helps to understand the time to irrigate, time to apply fertilizers, growth stages and evaluating the productivity of the crop etc. (You et al., 2013). In this study area, paddy, rubber, coconut and Arecanut are the grown. In addition, this is further helped us to identify the month which consists of all crops grown moderately or fully. Paddy is grown during both Rabi and summer seasons. During Rabi season paddy is sown in June and harvested in November or December. Thus, Coconut and Arecanut remains throughout the year. Rubber remains throughout year and sheds its leaves during late December and early January. In this study, both optical and SAR imagery of October was used because all three crops (e.g., Paddy, Coconut/ Arecanut, Rubber) are fully grown during this month.

\subsection{Agricultural land use/cover classification scheme}

In this study, seven land use/cover classes were selected for the classification based on literature review, local and national land use/cover classification scheme and land use management policy. Detailed of the selected land use/cover classes have explained in table 4.

\begin{tabular}{|l|l|l|}
\hline $\begin{array}{l}\text { Lulc } \\
\text { code }\end{array}$ & \multicolumn{1}{|c|}{ Classes } & \multicolumn{1}{|c|}{ Description } \\
\hline 1 & Paddy & Paddy fields and Paddy Cultivation \\
\hline 2 & Water Body & Lakes, Rivers and Reservoir \\
\hline 3 & Forest & $\begin{array}{l}\text { Evergreen Forest and Dry } \\
\text { Deciduous Forest }\end{array}$ \\
\hline 4 & Built Up & Urban areas and Semi urban areas \\
\hline 5 & Rubber & Rubber plantation \\
\hline 6 & Arecanut & Arecanut and Coconut plantation \\
\hline
\end{tabular}

\begin{tabular}{|l|l|l|}
\hline 7 & Barren land & Empty vacant land \\
\hline \multicolumn{3}{|c|}{ Table 4. Land Use Land Cover Classification scheme }
\end{tabular}

\subsection{Pre-processing}

The pre-processing generally includes radiometric and geometric correction, subsetting, mosaic and enhancement (Mustak, 2013) but in SAR, there are several others preprocessing were carried out (e.g., speckle reduction, calibration, terrain correction etc.) (See figure 2). The Sentinel-1A Ground range detected data which has terrain corrected gamma naught $\left(\gamma^{0}\right)$ backscatter values as the final output after processing (see figure 2A) which termed as intensity image.
(A)

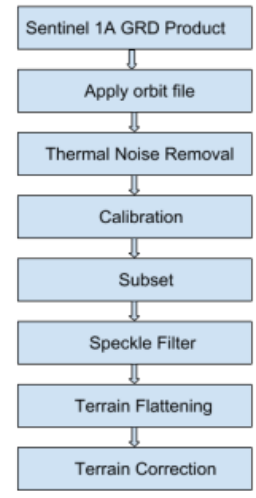

(B)

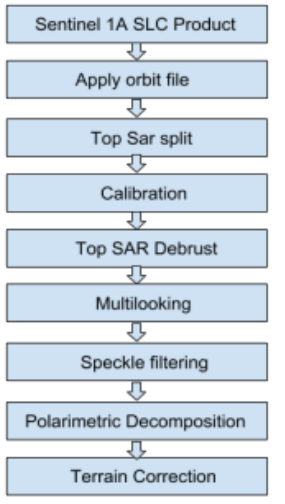

Figure 2. Pre-processing of Sentinel-1A, (A) GRD data; (B) SLC data

In addition, other pre-processing steps were used applying the orbit file which provides accurate satellite position and velocity information followed by thermal noise removal. Thus, the radiometric calibration was done to get beta naught $\left(\beta_{0}\right)$ which was further used for terrain correction (Small et al.,, 2012). This is then followed by subsetting the image to the selected study area and then used Refined Lee filter to reduce the speckles presence in the image. Furthermore, speckles corrected image was used for terrain flattening and terrain correction using the SRTM digital elevation model for correction topographic effects on image.

To enhance the overall classification of crops types using SAR data, Single look complex (SLC) data instead of GRD data was used to derive dual-pol polarimetric decomposition. Polarimetric decomposition provides added information of earth objects such as Volume scattering, surface scattering and double bounce which helps in the efficiently distinguishing detailed crops types. Figure (2B) shows the pre-processing of SLC data. In this study, we have used Dual Pole H- aangle polarimetric decomposition to obtain following decomposition indices such as Entropy $(H)$, alpha angle $(\alpha)$ and anisotropy (A). Entropy indicates the statistical randomness of the scattering while. Alpha angle indicates the average or dominant scattering mechanism within a specific target and the value ranges from 0 to $90^{\circ}$. Anisotropy is the measure of relative importance of second and third Eigenvalues and is the complementary parameter for entropy (Small et al., 2012).

In addition, radiometrically (TOA) and geometrically corrected Optical data was downloaded using google earth engine. Thus, others processing like sub setting, mosaicking of optical data was also done using median reducer using google earth engine. This is because median best representation the central tendency 
of the datasets instead of the others statistical measurement (e.g., mean, mode) (Kelley et al., 2018).

\subsection{Collection of training and test Samples}

In this study, training and test samples were randomly collected from the several sources such as Bhuvan land use/cover 20112012 (on 1:50,000 scale) using geo-web services (https://bhuvan-app1.nrsc.gov.in/thematic/ thematic/index.php), local knowledge and other ancillary datasets (e.g., article, research papers etc.). Adding to this local knowledge of the study area such as types of crop grown, crop growing period, types of urban settlement etc. are added advantages over traditional efforts to collect efficient and robust training and test samples. The training samples were collected from the aforementioned reference datasets using minimum 50 sample rule (e.g., minimum 50 training samples per class) using stratified random sampling because this strategy is more robust as compared others sampling techniques (Foody, 2009). In addition, stratified random sampling was employed to collect adequate test samples per class for efficient accuracy assessment. In some cases, (e.g., parameter tuning), training samples were splitting into training and validation set using $60: 40$ rules (e.g., $60 \%$ training and $40 \%$ validation).

\subsection{Image Classification}

Image classification was carried using following sub-processes:

3.5.1 Selected Machine Learning algorithms: Machine learning algorithm (MLA) is robust and increasingly used nonlinear statistical learning algorithms for multiclass problems. Initially, MLA was introduced in computer science for pattern recognition, computer vision but recently widely used in land use/cover classification from the satellite imagery (Kelley et al., 2018; Tsai et al., 2018). Recently, MLA in google earth engine widely used for land use/cover classification from satellite imagery because of its fast and efficient computation performance using high dimensional feature space (e.g., more related to big data) (Tsai et al., 2018). In google earth engine (GEE), three major supervised MLA are integrated such as Classification and Regression Tree (CART), Random Forest (RF) and Support Vector Machine (SVM) which were selected to explore their performance in crop discrimination.

In this study, pixel-based classification approach was employed using these MLA. In machine learning, SVM is one of the robust and widely used algorithms ensembles with several kernel functions (e.g., linear, polynomial, radial basis function etc.) in which radial basis function (RBF) is more robust as compared to others (Shi \& Yang, 2015; Tang et al., 2012). SVM-RBF has two important hyperparameters such as cost and gamma which affects the performance of the classifier and overall classification accuracy based on optimum hyperplane (Szuster et al., 2011). The cost explained the penalty over slack variables and more related to margin maximization while gamma explained the bandwidth of the RBF kernel (Mustak, 2018; Qian et al., 2014). Higher value of cost more the penalty over slack variables and similarly higher the value of gamma more is biases and lesser the variance and vices versa (Mustak, 2018; Qian et al., 2014). Generally, the range of cost is $10^{1}$ to $10^{2}$ and gamma is $10^{-2}$ to $10^{2}$ was selected in many studies for tuning hyperparameters of SVM-RBF (e.g., Mustak, 2018).

CART is a decision tree algorithm, which was initially used for data mining and forecasting (Adam et al., 2014). CART is also termed as binary decision tree which splits the training input (e.g., parents node) into different decision nodes (e.g., child, internal etc.) to obtain final leaf nods (e.g., external node, terminal, final class) based on the voting, splitting and logical inferences (e.g., If-else-than, pruning etc.) (Oliveira et al., 2017; Laliberte \& Rango, 2009). Splitting point in the decision tree is termed as root node (e.g., child node) which is assigned to a predicted class based on the distribution of classes. The root node is a series of internal nodes and terminal nodes. Each internal node consists of parent node and two or more child nodes. Based on the rules or the cost function, child node continues to split with the aid of regression until a leaf node is created (e.g., final predicted class) (Shi \& Yang, 2015). Parameter tuning (e.g., splitting rule, depth of tree etc.) in CART sometimes improved the overall classification accuracy in some context but readymade parameters used in CART as provided by GEE commonly performs higher classification accuracy in many cases.

Random forest (RF) is another important robust MLA configured tree-like which ensemble with several decision trees (Sun et al., 2016). Random forest creates several binary trees (ntree) using bootstraps sampling (sometimes called out-of-bag samples) which drawn from the number of training samples (mtry) randomly assigned in each node (e.g., child node). Final predicted class was obtained based on the maximum vote assigned in each class drawn from the deep ensemble decision tree (Adam et al., 2014; Sun et al., 2016). The overfitting of the RF mostly affected by the size of binary tree (ntree) instead of number of training samples assigned in each child node. Hence, tuning on size of tree (ntree) in RF was commonly used to reduce the overfitting and improve the overall classification accuracy because default value of mtry provided optimum result (Adam et al., 2014; Thanh Noi \& Kappas, 2017; Sun et al., 2016).

3.5.2 Features extraction and normalization: In this study, several image features such as spectral (e.g., image bands, NDVI, DEM), texture (e.g., GLCM) and contextual features (e.g., entropy, alpha angle and anisotropy) were extracted using GEE and SNAP.

- Image bands includes the spectral bands of Sential-2A (e.g., green, NIR etc.) and Sentinel-1A (e.g., VV, VH).

- Normalized Difference Vegetation Index (NDVI) is a robust spectral feature which is the added advantage over spectral bands to improve the overall classification accuracy. Because, it is very efficient to differentiate between vegetation area from the non-vegetated area (Julien et al., 2011; You et al., 2013). NDVI was computed using equation 1 :

$$
\text { NDVI }=\frac{N I R-R}{N I R+R}
$$

An NDVI value varies from +1 to -1 . NDVI value +1 explained the area having high vegetated area while NDVI value -1 explained the area with highly covers with nonvegetated area.

- Digital Elevation Model (DEM) is one of the important spectral features widely used in image classification. DEM used in the image classification especially in elevated landscape is the added advantage over other spectral features to improve the overall classification accuracy. This is because, in the undulating elevated landscape, distribution of land use varies with the height variation (Bahadur et al., 2009).

- Grey level Co-occurrence Matrix (GLCM) is a classical method for the extraction of texture feature from the 
image. In this study, GLCM mean was selected because of the robustness and widely used in many studies (Gevaert, et al., 2016; Ma et al., 2015). The GLCM mean was computed in all direction with the filter size 4 using GEE. GLCM mean features were extracted for all bands of optical image.

- Contextual image features such as entropy $(\mathrm{H})$, alpha angle $(\alpha)$ and anisotropy (A) were extracted from the SAR using SNAP to improve the classification accuracy. Entropy indicates statistical randomness of the scatters and its value varies from 0 to 1 . Entropy value 0 value indicates a single scattering while 1 indicates a mixture of scattering mechanism (Avtar et al., 2013). Alpha angle is another contextual feature computed using Eigen vectors. This is an indicative of average or dominant scattering mechanism of a specific target. The value of Alpha angle varies from 0 to 90 degree. Alpha angle value $0^{\circ}$ indicates odd bounce scattering from flat surfaces (e.g., waterbodies), value close to $45^{\circ}$ represents dipole or volume scattering (e.g., forest, plantation etc.) while values close to $90^{\circ}$ indicates double bounce scattering (e.g., builtup etc.) (Avtar et al., 2013). Anisotropy represents $2^{\text {nd }}$ and $3^{\text {rd }}$ Eigen values using Eigen decomposition. It is complementary parameter of entropy. It is useful when $\mathrm{H}$ $>0.7$ (Avtar et al., 2013).

- Fused image features such as optical image bands were merged with SAR (VV, VH) using High Pass Filter merge (HPF) in Erdas Imagine 2014. Fusion of SAR with optical image was widely used in many studies for land use/cover classification because of the enhancement of spectral and spatial resolution, and reduction of speckle effects (Mishra \& Susaki, 2014).

The above extracted image features were resampled to $10 \mathrm{~m}$ using nearest neighbour resampling method. In addition, final image features were normalized using equation 2:

$$
\text { Feature }_{\text {normalization }}=\frac{\text { Features- } M N(D N)}{M A X(D N)-M N(D N)}
$$

3.5.3 Features selection and parameter tuning: Feature selection is a very important consideration in image classification to reduce the effects of Hughes Phenomena and improve the overall classification accuracy (Pal \& Mather, 2004). It is also very important measures for class separability analysis. There are several feature selection methods such as principle component analysis (PCA), rank, and correlation etc. but sequential feature selection (SFS) method is robust and widely used (Mustak, 2018; Pal \& Mather, 2004). In addition, spectral plot was generated to visually inspect the class separability. In this study, SFS and spectral plot were used for feature selection. In addition, SVM-RBF (with default parameters) was used for evaluating accuracy of the different sets of image features using $60 \%$ training and $40 \%$ validation samples.

Beyond the feature selection, parameter tuning is another important attention to reduce the overfitting of the classifiers to improve the overall classification accuracy (Qian et al., 2014). In this study, holdout grid search 10 -fold cross-validation was used for tuning the best cost and gamma of SVM-RBF using cost range $10^{1}$ to $5 \times 10^{2}$ and gamma range $10^{-1}$ to $10^{2}$. Thus, 10 fold cross-validation was employed to select best ntree for RF using range 10 to 500 ntree. In addition, default parameters of CART were used for the classification. In parameter tuning 60 percent training samples were used training and 40 percent for validation.
3.5.4 Land use/cover classification and accuracy assessment: To classify the selected land use/cover, best features and parameters were used in SVM-RBF, RF and CART (also evaluated for other feature sets). In this classification, full training samples were used to train the classifiers while full test samples were used for final overall accuracy assessments. The overall accuracy was computed by dividing the sum of the diagonal values with the total values (e.g., sum of row and column) of the confusion matrix generated by classified and referenced land use classes.

\section{RESULTS AND DISCUSSIONS}

Results have been presented in the following sub-section using aforementioned methods to address the important research objectives:

\subsection{Training and test samples}

Based on the strategy employed for selecting training and test samples (see section 3.5.2) have been presented in the table 5 . Total 2281 training samples were used to train the classifiers while 1239 test samples were used for final overall accuracy.

\begin{tabular}{|c|c|c|}
\hline Classes & $\begin{array}{c}\text { Training data } \\
\text { (Pixels) }\end{array}$ & $\begin{array}{c}\text { Testing data } \\
\text { (Pixels) }\end{array}$ \\
\hline Paddy & 295 & 202 \\
\hline Water Body & 338 & 176 \\
\hline Forest & 299 & 180 \\
\hline Built Up & 374 & 161 \\
\hline Rubber & 322 & 177 \\
\hline Arecanut & 311 & 149 \\
\hline Barren land & 342 & 194 \\
\hline Total & 2281 & 1239 \\
\hline
\end{tabular}

Table 5. Statistics of training and testing data

\subsection{Extracted and normalized image features}

Table 6 shows the extracted and normalized features used for the crops discrimination using strategy made in section 3.5.2. These images features were further used the features selection to measure the class separability for improving the classification accuracy.

\begin{tabular}{|c|c|c|}
\hline $\begin{array}{l}\text { Image } \\
\text { features }\end{array}$ & Name of features & Number \\
\hline \multirow[t]{4}{*}{ Spectral } & 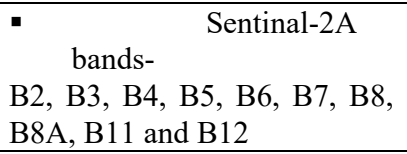 & 10 \\
\hline & - $\quad$ VV, VH & 02 \\
\hline & NDVI & 01 \\
\hline & DEM & 01 \\
\hline Texture & $\begin{array}{l}\text { GLCM mean of B2, B3, B4, } \\
\text { B5, B6, B7, B8, B8A, B11 } \\
\text { and B12 }\end{array}$ & 10 \\
\hline Contextual & $\begin{array}{l}\text { Polarimetric decomposition } \\
\text { indices such as entropy }(H) \text {, } \\
\text { alpha angle }(\alpha) \text { and anisotropy } \\
\text { (A) }\end{array}$ & 03 \\
\hline \multirow{2}{*}{$\begin{array}{l}\text { Fused } \\
\text { features }\end{array}$} & Optical+SAR VV & 10 \\
\hline & Optical+SAR VH & 10 \\
\hline \multicolumn{2}{|c|}{ Total features } & 47 \\
\hline
\end{tabular}

Table 6. Extracted and normalized image features. 


\subsection{Selected best Features}

Based on the strategy adopted for selecting best images features in the section 3.5.3, results have been presented in the table 7 and figure 3. Figure 3 shows that spectral reflectance of different land use/cover are varying with the different types of image features. In addition, table 7 shows that how overall classification accuracy is varying with the different sets of image features.

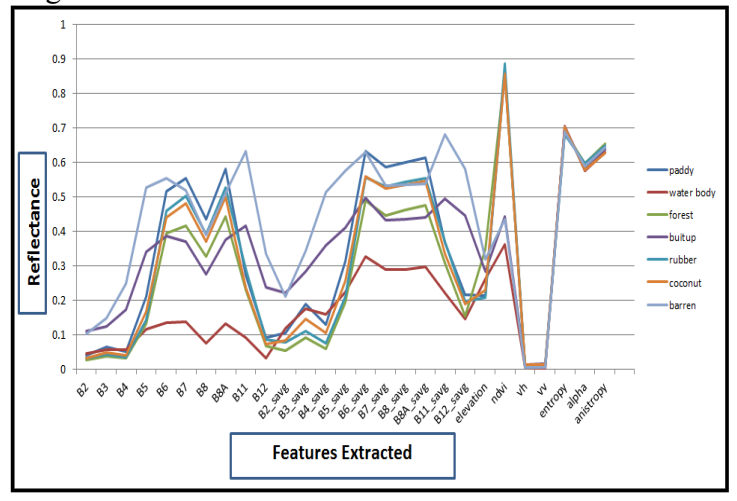

Figure 3. Spectral plot of features extracted versus Reflectance

\begin{tabular}{|c|c|c|}
\hline Features set & Name of features & $\begin{array}{c}\text { Overall } \\
\text { classification } \\
\text { accuracy }\end{array}$ \\
\hline Optical data & $\begin{array}{l}\text { Sentinel-2A : B2, B3, } \\
\text { B4, } \\
\text { B5,B6,B7,B8,B8A,B11 } \\
\text { and B12), GLCM of all } \\
\text { these bands, NDVI and } \\
\text { DEM }\end{array}$ & $98.45 \%$ \\
\hline SAR data & $\begin{array}{l}\text { Sentinel 1A (VH, VV) } \\
\text { and entropy (H), alpha } \\
\text { angle }(\alpha) \text { and anisotropy } \\
\text { (A) }\end{array}$ & $54.55 \%$ \\
\hline $\begin{array}{l}\text { Optical } \quad+ \\
\text { SAR }\end{array}$ & $\begin{array}{l}\text { Sentinel 2A: B2, B3, B4, } \\
\text { B5,B6,B7,B8,B8A,B11 } \\
\text { and B12), GLCM of all } \\
\text { these bands, NDVI and } \\
\text { DEM , SAR-VV, VH, } \\
\text { entropy (H), alpha angle } \\
(\alpha) \text { and anisotropy (A) }\end{array}$ & $98.96 \%$ \\
\hline $\begin{array}{l}\text { Fused VH } \\
\text { others } \\
\text { features } \\
\text { (spectral, } \\
\text { texture, } \\
\text { contextual) }\end{array}$ & $\begin{array}{l}\text { Fused Sentinel VH } \\
\text { polarisation and optical } \\
\text { imagery (B2, B3, B4, } \\
\text { B5,B6,B7,B8,B8A,B11 } \\
\text { and B12), GLCM of all } \\
\text { these bands, NDVI and } \\
\text { DEM , entropy (H), } \\
\begin{array}{l}\text { alpha angle ( }(\alpha) \text { and } \\
\text { anisotropy (A) }\end{array}\end{array}$ & $98.36 \%$ \\
\hline $\begin{array}{l}\text { Fused VV + } \\
\text { others } \\
\text { features } \\
\text { (spectral, } \\
\text { texture, } \\
\text { contextual) }\end{array}$ & 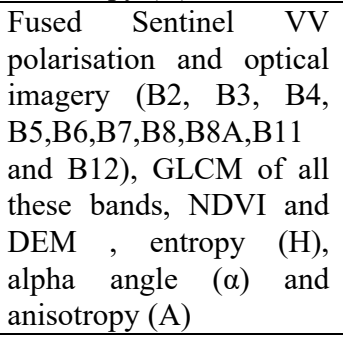 & $98.20 \%$ \\
\hline
\end{tabular}

Table 7. Evaluating best image features
The results show that optical and SAR along with others textural and contextual image features provided higher overall accuracy $(98.96 \%)$ as compared to others sets of image features. This is because, others advantages of SAR such as backscatter, surface roughness and dialectic constant, entropy $(\mathrm{H})$, alpha angle $(\alpha)$ and anisotropy (A) are the added contribution over the combination of optical images, NDVI and DEM for the improvement of overall classification accuracy (on $40 \%$ validation samples). These best image features have been used for parameter tuning, final land use/cover classification and overall accuracy assessment using selected machine learning algorithms.

\subsection{Selected best Parameters}

Using parameter tuning strategy as adopted in section 3.53, the best ntree of RF is 94 for all feature sets while best parameters of SVM-RBF are varied with different features sets. For the best features, best cost is 240 and gamma is 2.5 of SVM-RBF with $98.96 \%$ overall accuracy using validation samples (see table 8). Similarly, best feature, best ntree is 94 of RF with $97.36 \%$ overall accuracy using validation samples.

\begin{tabular}{|c|c|c|}
\hline Feature sets & Parameters used & Overall Accuracy \\
\hline Optical Data & $\begin{array}{c}\text { Gamma - } \\
\text { Cost }-100\end{array}$ & $98.45 \%$ \\
\hline SAR data & $\begin{array}{c}\text { Gamma - } \\
\text { Cost -100 }\end{array}$ & $54.55 \%$ \\
\hline $\begin{array}{c}\text { Optical +SAR } \\
\text { Fused VH + }+2.5 \\
\text { others features } \\
\text { (spectral, texture, } \\
\text { contextual) }\end{array}$ & $\begin{array}{c}\text { Gamma - 6.5 } \\
\text { Cost- } 91\end{array}$ & $98.96 \%$ \\
\hline $\begin{array}{c}\text { Fused VV + } \\
\text { others features } \\
\text { spectral, texture, } \\
\text { contextual) }\end{array}$ & Gamma - 3.5 & $98.35 \%$ \\
\hline
\end{tabular}

Table 8. Parameter tuning (SVM-RBF)

\subsection{Land use/cover classification and accuracy assessment}

Table 9 and figure 4 (a, b, c and d) shows the final land use/cover classification and accuracy assessment outcomes using different image features, best parameters and machine learning algorithms. The results show that optical +SAR outperforms the other feature sets and similarly, SVM-RBF outperforms the RF and CART and RF outperforms the CART. In addition, the quality of the classified map on optical + SAR data better as compared to the other feature sets.

\begin{tabular}{|c|c|c|c|}
\hline Feature sets & SVM-RBF & RF & CART \\
\hline Optical Data & $88.94 \%$ & $86.44 \%$ & $84.26 \%$ \\
\hline SAR data & $34.14 \%$ & $37.05 \%$ & $38.42 \%$ \\
\hline Optical +SAR & $88.94 \%$ & $88.05 \%$ & $85.47 \%$ \\
\hline $\begin{array}{c}\text { Fused VH + others } \\
\text { features } \\
\text { (spectral, texture, } \\
\text { contextual) }\end{array}$ & $85.07 \%$ & $84.91 \%$ & $81.03 \%$ \\
\hline
\end{tabular}




\begin{tabular}{|c|c|c|c|}
\hline $\begin{array}{c}\text { Fused VV + others } \\
\text { features } \\
\text { (spectral, texture, } \\
\text { contextual) }\end{array}$ & $85.23 \%$ & $85.79 \%$ & $76.76 \%$ \\
\hline
\end{tabular}

Table 9. Final classification accuracy using test samples

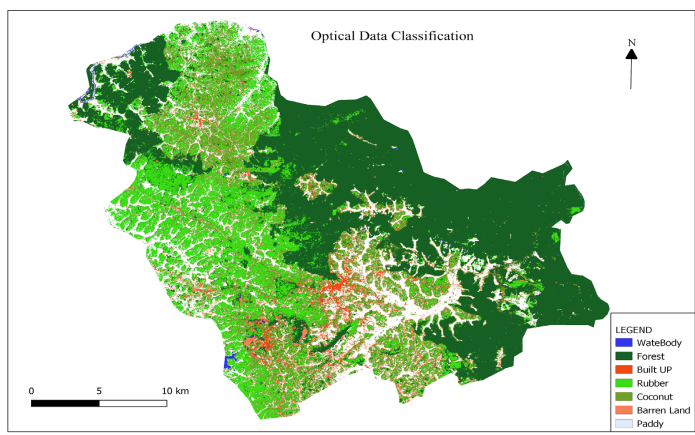

Figure 4(a). Classified map using Optical data (SVM-RBF)

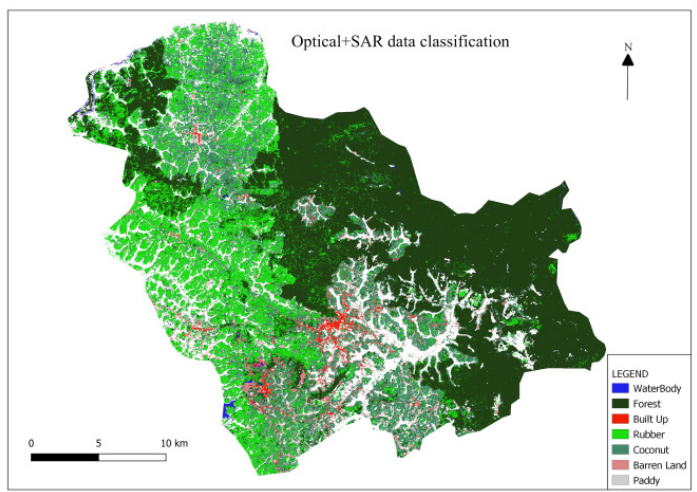

Figure 4(b). Classified map using Optical+ SAR data (SVM-RBF)

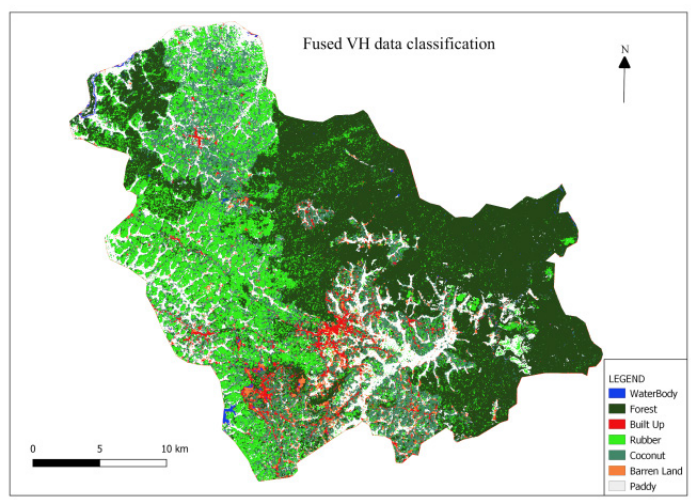

Figure 4(c). Classified map using Fused VH+ others data (SVM-RBF)

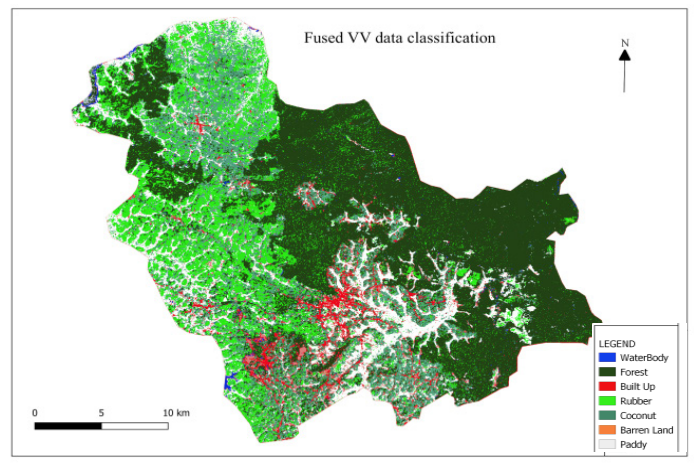

\section{CONCLUSION AND RECOMMENDATION}

As observed in this study, classification of the land use/cover using satellite imageries is a very challenging task. Recently, machine learning algorithms are playing a very important role for improving overall classification. This is because of the nonlinear computational efficiency and compatibility with big datasets (e.g., high dimensional features space). Beyond, the efficiency of machine learning algorithms, other parameters such types of image features, selection of optimum hyperparameters, size of training samples are also plays very important role for improving the overall classification accuracy. In this study, integration of optical data with SAR along with others texture and contextual image features are very important for the best discrimination of the different types of crops. In addition, SVM-RBF is a very efficient and robust classifier as compared to RF and CRAT for the classification of the crops types. However, classifiers have been train and test over very small area with limited training and test samples that may introduce some degree of biases for the implication of the model for bigger area. Therefore, it is recommended that training and testing of the classifiers over the larger area with sufficient amount of training and test samples are very essential to develop a robust land use/cover (e.g., crop discrimination) model.

\section{REFERENCES}

Adam, E., Mutanga, O., Odindi, J., \& Abdel-Rahman, E. M., 2014. Land-use/cover classification in a heterogeneous coastal landscape using RapidEye imagery: evaluating the performance of random forest and support vector machines classifiers. International Journal of Remote Sensing, 35(10), pp. 34403458. https://doi.org/10.1080/01431161.2014.903435.

Avtar, R., Takeuchi, W., \& Sawada, H., 2013. Full polarimetric PALSAR-based land cover monitoring in Cambodia for implementation of REDD policies. International Journal of Digital Earth, 6(3), pp. 255-275. https://doi.org/10.1080/17538947.2011.620639.

Bahadur, K.C., K., K.C., B., \& Krishna., 2009. Improving Landsat and IRS Image Classification: Evaluation of Unsupervised and Supervised Classification through Band Ratios and DEM in a Mountainous Landscape in Nepal. Remote Sensing, 1(4), pp. 1257-1272. https://doi.org/10.3390/rs1041257.

Balzter, H., Cole, B., Thiel, C., Schmullius, C., Balzter, H., Cole, B., Schmullius, C., 2015. Mapping CORINE Land Cover from Sentinel-1A SAR and SRTM Digital Elevation Model Data using Random Forests. Remote Sensing, 7(11), pp. 1487614898. https://doi.org/10.3390/rs71114876.

Cai, Y., Guan, K., Peng, J., Wang, S., Seifert, C., Wardlow, B., \& Li, Z. 2018. A high-performance and in-season classification system of field-level crop types using time-series Landsat data and a machine learning approach. Remote Sensing of Environment, 210, 2 pp. 35-47. https://doi.org/10.1016/J.RSE.2018.02.045.

de Oliveira Silveira, E. M., de Menezes, M. D., Acerbi Júnior, F. W., Castro Nunes Santos Terra, M., \& de Mello, J. M., 2017. Assessment of geostatistical features for object-based image classification of contrasted landscape vegetation cover. Journal of Applied Remote Sensing, 11(3), 036004.

Figure 4(d). Classified map using Fused VV+ others data (SVM-RBF) 
https://doi.org/10.1117/1.JRS.11.036004.

Engman, E. T., \& Chauhan, N., 1995. Status of microwave soil moisture measurements with remote sensing. Remote Sensing of Environment, 51(1), pp. 189-198. https://doi.org/10.1016/00344257(94)00074-W.

Foody, G. M., 2009. Sample size determination for image classification accuracy assessment and comparison. International Journal of Remote Sensing, 30(20), pp. 52735291. https://doi.org/10.1080/01431160903130937.

Gaetano, R., Cozzolino, D., D’Amiano, L., Verdoliva, L., \& Poggi, G., 2017. Fusion of sar-optical data for land cover monitoring. In 2017 IEEE International Geoscience and Remote Sensing Symposium (IGARSS), pp. 5470-5473. IEEE. https://doi.org/10.1109/IGARSS.2017.8128242.

Gevaert, C. M., Persello, C., \& Vosselman, G., 2016. Optimizing multiple kernel learning for the classification of UAV data. Remote Sensing, 8(12). https://doi.org/10.3390/rs8121025.

IMPRINT., (2018). Sulthan Bathery climate: Average Temperature, weather by month, Sulthan Bathery weather averages - Climate-Data.org. Retrieved January 8, 2019, from https://en.climate-data.org/asia/india/kerala/sulthan-bathery$37325 /$.

Jacobson, A., Dhanota, J., Godfrey, J., Jacobson, H., Rossman, Z., Stanish, A., Riggio, J., 2015. A novel approach to mapping land conversion using Google Earth with an application to East Africa. Environmental Modelling \& Software, 72, pp. 1-9. https://doi.org/10.1016/J.ENVSOFT.2015.06.011

Julien, Y., Sobrino, J. A., \& Jiménez-Muñoz, J.-C., 2011. Land use classification from multitemporal Landsat imagery using the Yearly Land Cover Dynamics (YLCD) method. International Journal of Applied Earth Observation and Geoinformation, 13(5), pp. 711-720. https://doi.org/10.1016/J.JAG.2011.05.008.

Kelley, L. C., Pitcher, L., Bacon, C., Kelley, L. C., Pitcher, L., \& Bacon, C., 2018. Using Google Earth Engine to Map Complex Shade-Grown Coffee Landscapes in Northern Nicaragua. Remote Sensing, 10(6), pp. 952 https://doi.org/10.3390/rs10060952.

Laliberte, A. S., \& Rango, A., 2009. Texture and scale in object-based analysis of subdecimeter resolution unmanned aerial vehicle (UAV) imagery. IEEE Transactions on Geoscience and Remote Sensing, 47(3), pp. 1-10. https://doi.org/10.1109/TGRS.2008.2009355.

Ma, L., Cheng, L., Li, M., Liu, Y., \& Ma, X., 2015. Training set size, scale, and features in Geographic Object-Based Image Analysis of very high resolution unmanned aerial vehicle imagery. ISPRS Journal of Photogrammetry and Remote Sensing, 102, pp. 14-27. https://doi.org/10.1016/j.isprsjprs.2014.12.026.

Mishra, B., \& Susaki, J., 2014. SAR and optical data fusion for land use and cover change detection. In 2014 IEEE Geoscience and Remote Sensing Symposium, pp. 4691-4694. IEEE. https://doi.org/10.1109/IGARSS.2014.6947540.
Mustak, S., 2013. Correction of atmospheric haze in resourcesat-1 LISS-4 mx data for urban analysis: An Improved Dark Object Subtraction approach. In International Archives of the Photogrammetry, Remote Sensing and Spatial Information Sciences - ISPRS Archives (Vol. 40).

Mustak, S., (2018). Evaluating The Performance Of Machine Learning Algorithms For Urban Land Use Mapping Using Very High Resolution. University of Twente. Retrieved from https://library.itc.utwente.nl/papers_2018/msc/upm/sheikh.pdf.

Pal, M., \& Mather, P. M., 2004. Assessment of the effectiveness of support vector machines for hyperspectral data. Future Generation Computer Systems, 20(7), pp. 1215-1225. https://doi.org/10.1016/J.FUTURE.2003.11.011.

Qian, Y., Zhou, W., Yan, J., Li, W., Han, L., Qian, Y., Han, L., 2014. Comparing Machine Learning Classifiers for ObjectBased Land Cover Classification Using Very High Resolution Imagery. Remote Sensing, 7(1), pp. 153-168. https://doi.org/10.3390/rs70100153.

Shao, Y., \& Lunetta, R. S., 2012. Comparison of support vector machine, neural network, and CART algorithms for the landcover classification using limited training data points. ISPRS Journal of Photogrammetry and Remote Sensing, 70, pp. 7887. https://doi.org/10.1016/j.isprsjprs.2012.04.001.

Shi, D., \& Yang, X., 2015. Support Vector Machines for Land Cover Mapping from Remote Sensor Imagery, pp. 265-279. Springer, Dordrecht. https://doi.org/10.1007/978-94-017-9813613.

Small, D., Zuberbühler, L., Schubert, A., \& Meier, E., 2012. Terrain-flattened gamma nought Radarsat-2 backscatter. Canadian Journal of Remote Sensing, 37(5), pp. 493-499. https://doi.org/10.5589/m11-059.

Song, Q., Hu, Q., Zhou, Q., Hovis, C., Xiang, M., Tang, H., Wu, W., 2017. In-Season Crop Mapping with GF-1/WFV Data by Combining Object-Based Image Analysis and Random Forest. Remote Sensing, 9(11), pp. 1184 https://doi.org/10.3390/rs9111184.

Sonobe, R., Yamaya, Y., Tani, H., Wang, X., Kobayashi, N., \& Mochizuki, K., 2017. Mapping crop cover using multi-temporal Landsat 8 OLI imagery. International Journal of Remote Sensing, 38(15), pp. 4348-4361. https://doi.org/10.1080/01431161.2017.1323286.

Steele-Dunne, S. C., McNairn, H., Monsivais-Huertero, A., Judge, J., Liu, P.-W., \& Papathanassiou, K., 2017. Radar Remote Sensing of Agricultural Canopies: A Review. IEEE Journal of Selected Topics in Applied Earth Observations and Remote Sensing, 10(5), pp. 2249-2273. https://doi.org/10.1109/JSTARS.2016.2639043.

Sun, X., Lin, X., Shen, S., \& Hu, Z., 2016. High-Resolution Remote Sensing Data Classification over Urban Areas Using Random Forest Ensemble and Fully Connected Conditional Random Field, pp. 1-22. https://doi.org/10.3390/ijgi6080245.

Szuster, B. W., Chen, Q., \& Borger, M., 2011. A comparison of classification techniques to support land cover and land use analysis in tropical coastal zones. Applied Geography, 31(2), pp. 525-532. https://doi.org/10.1016/J.APGEOG.2010.11.007. 
Tang, Q., Wang, L., Li, B., \& Yu, J., 2012. Towards a comprehensive evaluation of V-I-S sub-pixel fractions and land surface temperature for urban land-use classification in the USA. International Journal of Remote Sensing, 33(19), pp. 5996-6019. https://doi.org/10.1080/01431161.2012.675453.

Tsai, Y., Stow, D., Chen, H., Lewison, R., An, L., Shi, L., Shi, L., 2018. Mapping Vegetation and Land Use Types in Fanjingshan National Nature Reserve Using Google Earth Engine. Remote Sensing, 10(6), pp. 927. https://doi.org/10.3390/rs10060927.

Wu, S., Silvánhyphen;Cárdenas, J., \& Wang, L., 2007. Per-field urban land use classification based on tax parcel boundaries. International Journal of Remote Sensing, 28(12), pp. 27772801. https://doi.org/10.1080/014 31160600981541.

You, X., Meng, J., Zhang, M., Dong, T., You, X., Meng, J., Dong, T., 2013. Remote Sensing Based Detection of Crop Phenology for Agricultural Zones in China Using a New Threshold Method. Remote Sensing, 5(7), pp. 3190-3211. https://doi.org/10.3390/rs5073190. 